\title{
Volume of Distribution of Fraction Dose Observed Normalized by Surface Area
}

National Cancer Institute

\section{Source}

National Cancer Institute. Volume of Distribution of Fraction Dose Observed Normalized

by Surface Area. NCI Thesaurus. Code C92411.

The observed volume of distribution of the absorbed fraction associated with the terminal slope following extravascular administration, where F equals the fraction of dose absorbed, divided by the surface area. 